\title{
Mastite micótica em ruminantes causada por leveduras
}

\author{
Mycotic mastitis in ruminants caused by yeasts
}

\author{
Andréia Spanamberg ${ }^{\mathrm{I}, \mathrm{I}^{*}}$ Edna Maria Cavallini Sanches ${ }^{\mathrm{I}}$ Janio Morais Santurio $^{\mathrm{III}}$ \\ Laerte Ferreiro ${ }^{\mathrm{I}, \mathrm{II}}$
}

\section{- REVISÃo BIBLIOGRÁFICA -}

\section{RESUMO}

A ocorrência de casos esporádicos de mastite causados por microrganismos de origem ambiental pode ser considerada como emergente e as leveduras, os fungos leveduriformes e os filamentosos são alguns dos principais agentes envolvidos. Em relação à mastite micótica, as leveduras são freqüentemente causas de infecções da glândula mamária em animais produtores de leite. A maior parte dos casos ocorre sob a forma de surtos localizados e/ou após tratamento com antimicrobianos. Os principais gêneros envolvidos são Candida e Cryptococcus, além de outros como Geotrichum, Pichia e Trichosporon. O objetivo do trabalho é revisar os aspectos gerais sobre a mastite micótica causada por leveduras e fungos leveduriformes, tais como etiologia, causas predisponentes, patogenicidade, diagnóstico, tratamento e profilaxia por meio de uma abordagem cronológica dos primeiros relatos, mas com enfoque principal nos resultados descritos recentemente na literatura veterinária nacional e internacional. O controle da mastite micótica é fundamentado em métodos preventivos, como adequado manejo da ordenha, correta higienização dos equipamentos e das instalações, com a finalidade de reduzir o número de animais acometidos, além de garantir a qualidade e a inocuidade dos produtos lácteos.

Palavras-chave: mastite micótica, leveduras, fungos leveduriformes, Candida, Cryptococcus

\section{ABSTRACT}

The veterinary literature registers sporadic cases of infections caused by environmental microorganisms in which the main agents involved are yeasts, yeasts-like and filamentous fungi. In relation to dairy animals, the yeasts are more frequently incriminated as the aetiological agents of mycotic mastitis. Most cases occur under the form of localized outbreaks and / or after treatment with antimicrobial agents. The main genera involved in mastitis are Candida and Cryptococcus, besides others such as Geotrichum, Pichia and Trichosporon. The purpose of this review is to point out the main aspects of mastitis caused by yeasts and yeast-like fungi, such as etiology, predisposing factors, pathogenicity, diagnosis, treatment and prophylaxis, through a chronological approach of the first reports, with main focus on results described recently in national and international veterinary literature. The mycotic mastitis control should be mainly focused on preventive methods, especially based on adequate management of essential factors like proper milking procedures and a high level of hygiene of the environment and equipments, with the aim of reducing the number of affected animals, assuring the quality and innocuity of dairy food safety.

Key words: mycotic mastitis, yeasts, yeast-like, Candida, Cryptococcus.

\section{INTRODUÇÃO}

A mastite é um sério problema econômico no contexto da pecuária nacional. Os prejuízos ocorrem tanto na quantidade quanto na qualidade do leite produzido, com conseqüências no segmento da produção dos derivados lácteos.

IDepartamento de Patologia Clínica Veterinária, Setor de Micologia Veterinária, Faculdade de Veterinária, Universidade Federal do Rio Grande do Sul (UFRGS), Porto Alegre, RS, Brasil. E-mail: andreiaspanamberg@yahoo.com.br. *Autor para correspondência.

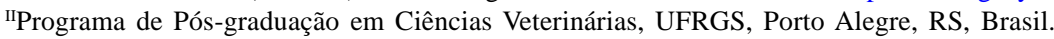

IIILaboratório de Pesquisas Micológicas (LAPEMI), Universidade Federal de Santa Maria, Santa Maria, RS, Brasil. 
Os agentes causadores de mastite são bactérias, fungos e algas, sendo as bactérias os agentes isolados com maior frequência (COSTA, 1991). Porém, cada vez mais, a literatura registra casos esporádicos de microrganismos de origem ambiental, entre os quais se destacam as leveduras, os fungos leveduriformes e os filamentosos. Apesar de os fungos filamentosos estarem amplamente distribuídos na natureza, eles são apenas esporadicamente isolados de casos de mastite, enquanto que as leveduras são os fungos que mais freqüentemente estão relacionadas às infecções da glândula mamária em animais produtores de leite (CHENGAPPA et al., 1984; KELLER et al., 2000).

A mastite micótica ocorre sob a forma de surtos localizados (CHAHOTA et al., 2001) e/ou após tratamento com antimicrobianos (CRAWSHAW et al., 2005) e são classificadas como primária ou secundária. A mastite primária ocorre espontaneamente, não é precedida por infecção bacteriana e/ou de tratamento com antimicrobianos, e é mais diagnosticada durante as primeiras semanas de lactação. Já a mastite micótica secundária, que é a forma clínica mais encontrada, se desenvolve após a administração de antimicrobiano intramamário para tratamento ou prevenção de casos de mastite bacteriana. Como em todos os casos de infecção da glândula mamária, a inoculação do agente pode ocorrer por via ascendente (via canal do teto) ou a partir de traumatismos cutâneos no teto e/ou no úbere. A população alvo em potencial compreende todos os animais produtores de leite. Aspectos relativos à produção animal como sistema intensivo ou extensivo empregado, tipo de ordenha (mecânica ou manual), além de outros fatores relativos à higiene de equipamentos e instalações utilizados, influenciam o aparecimento da enfermidade. Os principais gêneros envolvidos na mastite micótica são Candida e Cryptococcus, além de outros como Geotrichum, Pichia e Trichosporon (KUO \& CHANG, 1993; LAGNEAU et al., 1996; KRUKOWSKI et al., 2000).

O objetivo deste trabalho é revisar os principais aspectos ligados à mastite micótica causada por leveduras e fungos leveduriformes, tais como etiologia, causas predisponentes, patogenicidade, diagnóstico, tratamento e profilaxia por meio de uma abordagem cronológica dos primeiros relatos, mas com enfoque principal nos resultados descritos recentemente.

Leite como substrato para o crescimento de microrganismos

A riqueza de nutrientes presentes no leite propicia um excelente substrato para diversos microrganismos. A sua composição química favorece o crescimento de várias espécies de leveduras com diferentes perfis bioquímicos e fisiológicos, como, por exemplo, a habilidade de Kluyveromyces marxianus e Candida catenulata, entre outras, em metabolizar os constituintes lácteos (ROOSTITA \& FLEET, 1996). Ainda pode ser citada a capacidade de diversas leveduras em produzir enzimas como lipases e proteinases (CHEN et al., 2003; VACHLU \& KOUR, 2006) e fermentar diferentes açúcares, o que favorece o desenvolvimento nos produtos lácteos (FLEET \& MIAN, 1987).

\section{Mastite Micótica}

Atualmente, o estudo das micoses nos animais e no homem adquire uma importância cada vez maior devido ao fato de que muitas espécies de leveduras, fungos leveduriformes e filamentosos, anteriormente consideradas não-patogênicas, têm atuado como agentes oportunistas, causando enfermidades nos hospedeiros.

Em geral, as leveduras são consideradas sapróbicas e têm sido isoladas de tanques de armazenamento de leite oriundo de animais sadios (SPANAMBERG et al., 2004; RUZ-PEREZ et al., 2004). No entanto, em alguns casos, elas também estão presentes em amostras de leite provenientes de animais com mastite (CHENGAPPAet al., 1984; KUO \& CHANG, 1993; SANTOS \& MARIN, 2005; KRUKOWSKI et al., 2006).

Os agentes envolvidos na mastite micótica vivem no ambiente dos animais leiteiros, tais como na pele do teto, nas mãos dos ordenhadores e em vários substratos orgânicos (RICHARD et al., 1980; BARNETT et al., 2000). Este tipo de mastite ocorre sob a forma de surtos de casos clínicos, sejam isolados ou em vários animais, geralmente de curta duração, freqüentemente com manifestação aguda e com maior concentração nos momentos do pré e pós-parto imediato (CARBON, 1968). Vários aspectos influenciam o aparecimento de mastite micótica, entre eles o mau funcionamento do sistema de ordenha, o manejo inadequado da ordenha, a falta de higiene e a limpeza das instalações e dos equipamentos, além do uso prolongado de terapia antimicrobiana por via intramamária (RUZ-PEREZ et al., 2004; YAMAMURA et al., 2007)

No Brasil, no Estado de São Paulo, o isolamento de $\boldsymbol{C}$. albicans ocorreu em 8,9\% de 260 amostras leite de vacas com mastite (SANTOS \& MARIN, 2005). No Rio Grande do Sul, FERREIRO et al. (1985) detectaram, em 896 amostras de leite mamítico, a 
presença de Candida spp. em 1,3\% da amostragem, das quais $0,9 \%$ eram Candida albicans. Posteriormente, outro estudo no mesmo Estado não detectou a presença de $\boldsymbol{C}$. albicans no leite de animais com mastite clínica e subclínica, apesar de as espécies do gênero Candida representarem 37,9\% dos isolados fúngicos (SPANAMBERG et al., 2008a).

Em outra pesquisa realizada em São Paulo, com 2.078 amostras de leite de quartos normais e de quartos infectados, foi observado que 10,0\% (208) correspondiam a leveduras, sendo 3,2\% (66) pertencentes ao gênero Candida (COSTA et al. 1993). Nos Estados Unidos da América, RICHARD et al, (1980) cultivaram 91 isolados do leite de animais com mastite clínica e subclínica, com predominância do gênero Candida (78\%), principalmente Candida tropicalis e Candida rugosa. Ainda nesse estudo, espécies como Candida tropicalis, C. rugosa, C. parapsilosis e Cryptococcus lactativorus foram utilizadas em estudos experimentais de patogenicidade na glândula mamária, com a observação do desencadeamento da enfermidade em todos os quartos inoculados e a cura espontânea do quadro de mastite de 10 a 30 dias após a inoculação. Na Dinamarca, a partir de 2.896 amostras, AALBAEK et al. (1994) obtiveram 45 isolados, entre os quais Candida kefir, C. krusey, C. catenulata, $C$. rugosa, C. tropicalis, C. valida e Geotrichum capitatum, além da alga Prototheca zopfii.

Na Polônia, KRUKOWSKI et al. (2000) isolaram diversas espécies de Candida, Rhodotorula e Trichosporon no leite coletado de 172 vacas com mastite clínica e subclínica. VICTORIA \& LANGONI (2006) relatam a ocorrência de mastite clínica e subclínica causada por Trichosporon beigelli em rebanho leiteiro no Estado de São Paulo. Por outro lado, em outros trabalhos desenvolvidos com leite bovino e caprino in natura no Rio Grande do Sul, Trichosporon spp. foram encontradas em baixa freqüência e não associadas à mastite (SPANAMBERG et al., 2004, SPANAMBERG et al., 2006). O genêro Trichosporon, quando isolado do leite e de produtos lácteos, pode indicar falta de higiene nas instalações e dos equipamentos durante a obtenção e o processamento dos mesmos (WESSTAL \& FILTENBORG, 1998).

Quanto aos pequenos ruminantes, são poucos os relatos de mastite micótica, porém, MOAWAD \& OSMAN (2005), em pesquisa realizada no Egito, detectaram a presença de leveduras (5,13\%) em 196 amostras de leite de ovelha provenientes de animais com mastite subclínica.

O desencadeamento da mastite micótica em vacas e cabras ocorre usualmente após terapia antimicrobiana (THOMPSON et al., 1978; JENSEN et al., 1996; VESTWEBER \& LEIPOLD, 1995). O uso de antimicrobianos por um período prolongado é apontado como o principal fator que favorece a ocorrência de mastite micótica, por afetar a microbiota que atua, quando em equilíbrio, como defesa natural do animal. Por exemplo, as leveduras do gênero Candida podem utilizar a penicilina e a tetraciclina como fontes de nitrogênio (LOFTSGARD \& LINDQUIST, 1960), fato que enfatiza a relevância da implementação de um adequado manejo para prevenir a infecção. Existe também a possibilidade de as soluções antimicrobianas estarem contaminadas com fungos, os quais podem ser inoculados e provocar mastite (THOMPSON et al., 1978; JENSEN et al., 1996).

Outro aspecto ligado ao uso inadequado de antimicrobianos via intramamária é o fato de algas aclorofiladas, sobretudo as do gênero Prototheca, serem consideradas como causa emergente de mastites subclínicas em bovinos, embora a casuística seja, muitas vezes, subdiagnosticada. Além deste fato, é preciso considerar o potencial zoonótico e sua resistência a diversos fármacos utilizados, entre eles penicilina e gentamicina, além de uma particular resistência à pasteurização (ALMEIDA et al., 2005). Cabe salientar ainda a importância do correto diagnóstico de Prototheca spp., uma vez que algumas espécies, como Prototheca wicherhamii, apresentam perfil bioquímico semelhante ao de algumas leveduras, como, por exemplo Candida glabrata (KOEHLER et al., 1999), o que torna fundamental o estudo da morfologia celular do organismo analisado.

As principais espécies fúngicas associadas à mastite pertencem aos gêneros Candida e Cryptococcus, embora espécies de Trichosporon, Rhodotorula e Geotrichum, entre outros, também estejam associadas (Tabela 1). A maioria dos isolamentos de leveduras de leite mamítico de ruminantes se refere à espécie bovina, além das espécies ovina, caprina e bubalina (COSTA et al., 1993; CORBO et al., 2001; MOAWAD \& OSMAN, 2005; CARVALHO et al., 2007).

\section{Mastite por Candida spp.}

Candida spp. vivem normalmente em saprobiose, mas em circunstâncias propícias podem desenvolver seu potencial patogênico. Usualmente, a presença de Candida spp. no leite ocorre sem patogenia associada, embora possa causar mastite nas formas subclínica, clínica ou crônica (WAWRON \& SZCZUBIAL, 2001). Dependendo da gravidade da infecção, a queda da produção de leite pode ser rápida, 
Tabela 1 - Espécies de leveduras e fungos leveduriformes associados à mastite.

\begin{tabular}{|c|c|c|c|}
\hline Ano & País & Espécies associadas à mastite & Autor \\
\hline 2008a & Brasil & $\begin{array}{l}\text { Pichia guilliermondii, Galactomyces geotrichum, Rhodotorula minuta, R. } \\
\text { glutinis, Candida rugosa, C. catenulata, C. zeylanoides, C. glabrata, } \\
\text { Cryptococcus laurentii }\end{array}$ & SPANAMBERG et al. \\
\hline 2008 & Brasil & Candida spp. & YAMURA et al. \\
\hline 2006 & Polônia & $\begin{array}{l}\text { Rhodotorula spp. Cryptococcus spp., Pichia spp., Trichosporon cutaneum, } \\
\text { Candida krusei, C. tropicalis, C. albicans }\end{array}$ & KRUKOWSKI et al. \\
\hline 2006 & Brasil & Trichosporon beigelli & VICTORIA \& LANGONI \\
\hline 2005 & Brasil & $\begin{array}{l}\text { Candida albicans, C. kefyr, C. humicola, , C. inconspicua, C. guilliermondii, } \\
\text { C. parapsilosis, C. zeylanoides, C. famata, C. tropicalis, C. rugosa }\end{array}$ & SANTOS \& MARIN \\
\hline 2005 & Inglaterra & Candida rugosa & CRAWSHAW et al. \\
\hline 2001 & India & Geotrichum candidum & CHAHOTA et al. \\
\hline 2000 & Polônia & $\begin{array}{l}\text { Candida albicans, C. kefyr, C. ciferri, C. krusey, C. tropicalis, C. humicola, C. } \\
\text { parapsilosis, Rhodotorula glutinis, Trichosporon cutaneum, T. capitatum }\end{array}$ & KRUKOWSKI et al. \\
\hline 1998 & Itália & $\begin{array}{l}\text { Trichosporon capitatum, T. beigelii, Candida albicans, C. guillermondii, C. } \\
\text { tropicalis }\end{array}$ & MORETTI A. \\
\hline 1997 & Bélgica & Candida rugosa, C. kefyr, Debaryomyces hansenii, Pichia kluyveri & SWINNE et al. \\
\hline 1996 & Bélgica & Candida kefyr, C. catenulata, C. lambica & LAGNEAU et al. \\
\hline 1996 & Polônia & $\begin{array}{l}\text { Trichosporon beigelli, Geotrichum candidum, Candida albicans, C. krusei, } \\
\text { C. pseudotropicalis, C. tropicalis, C. parapsilosis, C. rugosa }\end{array}$ & $\begin{array}{l}\text { KRZYZANOWSKI \& } \\
\text { SIELICKA }\end{array}$ \\
\hline 1995 & Israel & Candida krusei & ELAD et al. \\
\hline 1994 & Dinamarca & Candida tropicalis, C. krusei, C. valida, C. kefyr, Geotrichum capitatum & AALBAEK et al. \\
\hline 1993 & Japão & $\begin{array}{l}\text { Candida tropicalis, C. parapsilosis, C. rugosa, C. albicans, C. guilliermondii, } \\
\text { Geotrichum candidum, Trichosporon beigelli }\end{array}$ & KUO \& CHANG \\
\hline 1993 & Brasil & $\begin{array}{l}\text { Candida albicans, C. catenulata, C. ciferri, C. famata, C. tenuis, C. tropicalis, } \\
\text { C. guilliermondii, C. haemulonii, C. intermedia,C. krusei, C. zeylanoides, C. } \\
\text { magii, C. parapsilosis, C. rugosa, C. shetae, C. sorbosa, Cryptococcus } \\
\text { albidus,C. flavus, C. laurentii, C. luteolus }\end{array}$ & COSTA et al. \\
\hline 1988 & Coréia & Candida albicans, Candida spp. & YEH et al. \\
\hline 1980 & EUA & Candida tropicalis, C. rugosa, Cryptococcus lactivorus. & RICHARD et al. \\
\hline
\end{tabular}

apresentando alterações macroscópicas no leite com formação de flocos e grumos (CARBON, 1968).

Candida albicans, integrante normal da microbiota gastrintestinal dos mamíferos (ODDS, 1988), é a espécie mais freqüentemente isolada e descrita em casos de mastite micótica. Por meio de inoculações experimentais, por via intramamária, em ovelhas e cabras, já foi demonstrada a capacidade patogênica desta espécie. Mesmo sem o uso prévio de terapia antimicrobiana e na ausência de fatores imunossupressores, ocorreu o desenvolvimento de um quadro inicialmente agudo e purulento, que gradualmente tornou-se crônico, não-purulento e com formação de granulomas. A queda na produção leiteira é rápida, podendo até ocorrer agalaxia com lesões teciduais que podem ser extensas e irreversíveis. As lesões são restritas aos quartos mamários inoculados, sem disseminação aos outros quartos e aos outros orgãos do corpo (CARBON, 1968). Inoculações experimentais de Candida tropicalis em vacas demonstraram igualmente elevada patogenicidade desta levedura para a glândula mamária (KUO, 1993).

Estudos indicam a participação de espécies não-albicans cada vez mais associadas a patologias da glândula mamária (OLIVEIRA et al., 2001; CRAWSHAW et al., 2005), principalmente de espécies como Candida tropicalis, C. guilliermondii, $C$. luzitanae, C.kefyr, C. rugosa, C. catenulata, C. zeylanoides, C. lambica e $\boldsymbol{C}$. inconspicua (LOKEN et al., 1959; COSTA et al., 1993; LAGNEAU et al., 1996; SWINNE et al., 1997; SANTOS \& MARIN, 2005). Em estudo realizado no Rio Grande do Sul (SPANAMBERG et al., 2008a), a identificação de espécies como Candida aaseri, $C$. caseynolitica, $C$. saitoana e $C$. sorbophila confirma a variada gama etiológica potencialmente presente no leite, o que corrobora a hipótese de que espécies normalmente consideradas não-patogênicas podem, em condições propícias, causar danos à glândula mamária. 
Mastite por Cryptococcus spp.

A criptococose mamária pode ser esporádica ou enzoótica em certas situações. Na maioria das vezes, ela está associada à mastite clínica e, em menor porcentagem, aos casos subclínicos (LANGONI et al., 1998; KLOSSOWSKA \& MALINOWSKI, 2001), podendo ter evolução aguda ou crônica (PAL, 1991). Dependo do quadro clínico, o animal pode apresentar agalaxia em poucas semanas. Na forma aguda, o comprometimento do parênquima mamário pode ser observado pela presença de fibrose, nódulos necróticos e algumas vezes hemorrágicos. Esse tipo de infecção normalmente fica restrita aos quartos infectados e sem comprometimento sistêmico (VERMA et al., 1985; MANJEET et al., 1994).

A literatura registra diversos casos de mastite causados por Cryptococcus spp. em bovinos (KIRK \& BARTLETT, 1986; LANGONI et al., 1998; KLOSSOWSKA \& MALINOWSKI, 2001), bubalinos (PAL, 1991), ovinos (SHNAWA \& NIGAM, 1987), assim como em caprinos (CONTRERAS et al., 1995).

A espécie mais freqüentemente implicada é Cryptococcus neoformans, considerada uma das mais patogênicas, e que já foi isolada de vários casos de mastite clínica, subclínica e também do leite de vacas sadias (EBRAHIMI \& NIKOOKHAH, 2002). Outras espécies, como Cryptococcus laurentii e C. curvatus, também já foram isoladas de casos de mastite bovina (COSTA et al., 1993; KLIMAITE et al., 2003), leite de cabra in natura (SPANAMBERG et al., 2006) e em tanque de armazenamento de leite (SWINNE et al., 1997).

\section{Causas predisponentes}

A maioria dos casos de mastite ocorre por via ascendente, com a penetração dos microrganismos via canal do teto, durante ou entre as ordenhas, assim como durante a administração intramamária de antibióticos (CRAWSHAW et al., 2005). Devido ao fato de as leveduras serem encontradas em uma grande variedade de substratos, como, por exemplo, no epitélio da glândula mamária, nos tetos, nas mãos dos ordenhadores, no solo e na água (RICHARD et al., 1980; BARNETT, 2000), a possibilidade de ocorrência da doença aumenta quando está aliada à contaminação ambiental e à falta de higiene na ordenha e nos equipamentos.

\section{Patogenicidade}

A aderência de qualquer microrganismo nos tecidos do interior da glândula favorece a instalação da infecção, dificultando sua remoção mecânica pelo fluxo do leite durante a ordenha. Caso ocorra uma falha nos mecanismos de defesa do sistema imunológico, os microrganismos inicialmente se instalam nos ductos e nas cisternas e posteriormente progridem para pequenos ductos e alvéolos das porções mais baixas do úbere, onde se multiplicam, provocando edema e destruição das células secretoras (RAINARD \& RIOLLET, 2006).

Especificamente em relação às mastites micóticas, o principal fator para a o desenvolvimento do quadro é a administração de antimicrobianos diretamente no canal do teto, os quais podem favorecer a multiplicação fúngica e/ou destruir a microbiota que sintetiza certas vitaminas. KAUKER (1955), por meio de estudos experimentais, observou que o tratamento prolongado com penicilina induz uma redução de vitamina $A$, situação que favorece o aparecimento de lesões na mucosa, o que facilitaria a penetração e a instalação das leveduras no parênquima mamário.

\section{Diagnóstico}

Os sinais clínicos das mastites micóticas, na maior parte dos casos, não podem ser distinguidos das mastites bacterianas. Entretanto, o uso de antimicrobiano intramamário sem sucesso no tratamento ou a intensificação dos sintomas, com a continuidade da terapia, pode sugerir o desenvolvimento de uma etiopatogenia fúngica. Para o esclarecimento do agente etiológico envolvido, amostras de leite podem ser coletadas para imediato processamento no laboratório ou então serem congeladas por períodos inferiores a 10 dias, porque após este limite a viabilidade das leveduras começa decrescer (SPANAMBERG et al., 2008b).

Atualmente, existem diversos procedimentos utilizados para facilitar a rotina laboratorial de identificação das leveduras. Entre eles destaca-se a utlização dos meios cromogênicos (CHROMagar Candida/Candida ID bioMérieux ${ }^{\circledR}$ SA), empregados na triagem e na identificação rápida de espécies patogênicas como Candida albicans, $\boldsymbol{C}$. parapsilosis, C. glabrata e $\boldsymbol{C}$. krusei, além dos testes bioquímicos que podem ser realizados por meio do padrão de assimilação de substratos existentes no sistema de galerias API 20 e API 32 (bioMérieux ${ }^{\circledR}$ SA), ambos processados segundo a indicação do fabricante. O grande entrave para a utilização destes testes e de outros já disponiveis é o alto custo e a baixa procura por diagnóstico fúngico nos laboratórios de medicina veterinária.

A metodologia convencional para a identificação laboratorial das leveduras envolve a observação de características fenotípicas dos isolados (macromorfologia e micromorfologia), a realização de 
testes rápidos, tais como formação de tubo germinativo e produção de clamidosporos (Candida albicans), além de outros testes bioquímicos e fisiológicos complementares para o diagnóstico das demais espécies (YARROW, 1998; NEUFELD, 1999; BARNETT et al., 2000; CHABASSE, 2006).

É reconhecido o fato de que a caracterização fenotípica de leveduras pode apresentar erros, pois várias espécies apresentam similaridades morfológicas nos testes bioquímicos e fisiológicos. Recentemente, novas técnicas moleculares têm sido desenvolvidas para identificar e caracterizar microrganismos provenientes de leite cru e queijos (COCOLIN et al., 2002; CALLON et al., 2006; LOPANDIC et al., 2006).

Tratamento

Apesar do aumento no número de antifúngicos comercialmente disponíveis nos últimos anos para o tratamento de diversas micoses humanas e animais, são raros os fármacos antimicóticos disponibilizados em veículo adequado para o tratamento da mastite micótica, principalmente quando comparados aos medicamentos antimicrobianos usualmente empregados para combater a doença de origem bacteriana.

A literatura registra poucos dados específicos sobre tratamento contra mastite fúngica, mas alguns autores citam a nistatina, a natamicina, o fluconazol e o miconazol em solução aquosa para o tratamento intramamário em vacas com mastite por Candida sp. (NOBRE et al., 2002; KRUKOWSKI \& SABA, 2003). Um recente estudo avaliou a susceptibilidade antifúngica de 319 leveduras isoladas do leite de animais com mastite e demostrou que mais de $75 \%$ dos isolados apresentou resistência à Anfotericina-B, 66\% ao Fluconazole, 40\% ao Primaricin e ao Itraconazole (LASSA \& MALINOWSKY, 2007).

Exceto na infecção por Cryptococcus spp., a mastite micótica, na maioria das vezes, é autolimitante, apresentando uma fase aguda com recuperação espontânea sem uso de antifúngicos (CARBON, 1968; PENGOV, 2001; CRAWSHAW et al., 2005). Geralmente, o tratamento suporte utilizado visa diminuir os sinais clínicos e não combater o agente etiológico específico (AINSWORTH \& AUSTWICK, 1959). Nos casos agudos de mastite, é altamente recomendável o esgotamento freqüente da glândula mamária com utilização de ocitocina (6-8 vezes/dia), antiinflamatórios, além de intensa fluidoterapia intravenosa.

Profilaxia

Práticas higiênicas inadequadas prejudicam a qualidade do leite e predispõem a ocorrência de mastite. A prevenção é fundamental para o controle da mastite. As instalações como sala de ordenha e curral de espera, por onde circulam os animais antes, durante e após a ordenha, devem ser mantidas limpas e secas, para evitar a multiplicação de microrganismos. Na limpeza diária, é fundamental a remoção das fezes para reduzir a proliferação de moscas e outros parasitas. Utensílios e objetos de ordenha devem ser limpos e adequadamente desinfetados após cada ordenha.

A correta higiene do ordenhador é outro ponto fundamental, pois as mãos atuam como veículo transmissor de microrganismos, entre eles leveduras, as quais podem contaminar o úbere, o leite e todo o material utilizado. Outros aspectos a serem considerados em um programa de controle de mastite incluem a imersão dos tetos pré e pós-ordenha com desinfetante germicida, descarte dos animais com diagnóstico de mastite crônica, além da correta manutenção do equipamento da ordenha com a finalidade de evitar traumatismos mecânicos (RADOSTIS et al., 2002).

Outro ponto importante na resistência da glândula mamária às infecções é a dieta, pois a carência de certos nutrientes afeta os mecanismos de defesa, como, por exemplo, a atividade dos leucócitos, transporte de anticorpos e integridade do tecido glandular. Desse modo, alguns autores sugerem, por exemplo, a suplementação com selênio e vitamina E. (PASCHOAL et al., 2003).

\section{CONCLUSÕES}

A diversificada gama de agentes potencialmente causadores de mastite micótica ressalta a importância da realização concomitante de exames micológicos e bacteriológicos para o correto diagnóstico e monitoramento dos casos de mastite. Uma vez constatada a etiologia fúngica, deve-se evitar o tratamento com antibacterianos, os quais, além de não exercerem efeito terapêutico, podem favorecer a proliferação de fungos na glândula mamária em determinadas circunstâncias.

Em relação à saude pública, o leite, quando contaminado e ingerido in natura, assim como os produtos lácteos produzidos a partir de leite cru, podem ser veiculadores de uma grande diversidade de agentes potencialmente patogênicos.

No que concerne à produção de derivados lácteos, a contaminação do leite por leveduras pode afetar o produto final por meio de alterações organolépticas que ocorrem pela produção de enzimas lipolíticas e proteolíticas, além de outros derivados 
metabólicos produzidos pelas leveduras e pelos fungos leveduriformes.

O controle da mastite micótica e de origem bacteriana deve ter como base principalmente os métodos preventivos, em que se torna essencial a implementação efetiva de medidas como o correto manejo e a adequada higiene na ordenha (pré-dipping, pós-dipping e ordenha de tetos limpos e secos). Essas ações incluem a obtenção do leite e a limpeza dos equipamentos e das instalações, que reduzem a porcentagem de animais acometidos e melhoram a qualidade do leite produzido, além de aumentarem a rentabilidade econômica da pecuária leiteira.

\section{AGRADECIMENTOS}

Ao Conselho Nacional de desenvolvimento Científico e Tecnológico (CNPq), pelo suporte financeiro a este trabalho.

\section{REFERÊNCIAS}

AALBAEK, B. et al. Mycotic and algal bovine mastitis in Denmark. Acta Pathologica, Microbiologica et Immunologica, v.102, p.451-456, 1994.

AINSWORTH, G.C.; AUSTWICK, P.K.C. Fungal Diseases of Animals - Review Series, n.6, p.148, 1959.

ALMEIDA, L.A. do B. et al. Tratamento de mastite clinica experimental por meio de ordenhas multiplas em vacas leiteiras inoculadas com Staphylococcus aureus. Arquivo Instituto Biológico, v.72, p.1-6, 2005.

BARNETT, J.A. et al. Yeast, characteristics and identification. 3.ed. Cambridge: Cambridge University, 2000. 1150p.

CALLON, C. et al. Application of SSCP- PCR fingerprinting to profile the yeast community in raw milk Salers cheeses. Systematic and Applied Microbiology, v.29, p.172-180, 2006.

CARBON, J.P. Contribution à l'étude de mamite mycosique de la vache. 1968. 59f. Tese Doutorado em Veterinária - École Nationale de Vétérinaire D’Alfort (ENVA) - França.

CARVALHO, L.B. et al. Contagem de células somáticas e isolamento de agentes causadores de mastite em búfalas (Bubalus bubalis). Arquivo Brasileiro de Medicina Veterinária e Zootecnia, v.59, n.1, p.242-245, 2007.

CHABASSE, D. et al. Candida pathogènes. Paris: Lavoisier, 2006. 183p.

CHAHOTA, R. et al. Clinical bovine mastitis caused by Geotrichum candidum. Veterinarski ARHIV, v.71, p.197201, 2001.

CHEN, L. et al. Detection and impact of protease and lipase activities in milk and milk powders. International Dairy Journal, v.13, p.255-275, 2003.
CHENGAPPA, M.M. et al. Isolation and Identification of Yeasts and Yeastlike Organisms from Clinical Veterinary Sources. Journal of Clinical Microbiology, v.19, p.427-428, 1984.

COCOLIN, L. et al. An application of PCR-DGGE analysis to profile the yeast populations in raw milk. International Dairy Journal, v.12, p.407-411, 2002.

CONTRERAS, A. et al. Prevalency and aetiology of nonclinical intramammary infection in Murciano-Granadina goats. Small Ruminant Research, v.17, p.71-78, 1995.

CORBO, M.R. et al. Occurrence and characterization of yeasts isolated from milks and dairy products of Apulia region. International Journal of Food Microbiology, v.69, p.146152, 2001.

COSTA, E.O. Importância econômica da mastite infecciosa bovina. Revista da Faculdade de Medicina Veterinária e Zootecnia da Universidade de São Paulo, v.1, p.21-26, 1991.

COSTA, E.O. et al. Survey of bovine mycotic mastitis in dairy herds in the State of São Paulo, Brazil. Mycopathologia, v.124, p.13-17, 1993

CRAWSHAW, W.M. et al. Outbreak of Candida rugosa mastitis in a dairy herd after intramammary antibiotic treatment. Veterinary Records, v.156, p.812-813, 2005.

EBRAHIMI, A.; NIKOOKHAH, F. Investigation of Cryptococcus neoformans in milk samples of normal, acute and chronically mastitic cows of Shahrekord district. Iranian Journal of Veterinary Research, v.3, p.179-182, 2002.

ELAD, D. et al. Feed contamination with Candida krusei as a probable source of mycotic mastitis in dairy cows. Journal of the American Veterinary Medical Association, v.207, p.620-602, 1995.

FERREIRO, L. et al. Mastite bovina na Grande Porto Alegre, RS - Brasil. Arquivos da Faculdade de Veterinaria - UFRGS, v.13, p.81-88, 1985.

FLEET G.H.; MIAN M.A. The occurrence and growth of yeasts in dairy products. International Journal of Food Microbiology, v.4, p.145-155, 1987.

JENSEN, H.E. et al. Caprine mastitis due to Aspergillosis and Zygomycosis: a pathological and immunohistochemical study. Journal of Comparative Pathology, v.114, p.183-191, 1996.

KAUKER, E. Ueber mastitis-blastomyceten. B erliner und Münchener Tier Wock, v.68, p.407, 1955. KELLER, B. et al. Differentiation of yeasts in mastitis milk. Mycoses, v.1, p.17-19, 2000.

KLIMAITE, J. et al. Etiology yeasts and other microorganisms of subclinical mastitis in cows. Veterinarija ir Zootechnika, v.23, p.5-9, 2003.

KIRK, J.H.; BARTLETT, P.C. Bovine mycotic mastitis. Compendium on Continuing Education for the Practicing Veterinarian, v.8, p.F106-F110, 1986. 
KLOSSOWSKA, A.; MALINOWSKI, E. Pathogens in raw milk which affect humans. Medycyna Weterynaryjna, v.57, p.2831,2001

KOEHLER, A.P. et al. Simple, reliable and cost-effective yeast identification scheme for the clinical laboratory. Journal of Clinical Microbiology, v.37, p.422-426, 1999.

KRUKOWSKI H., et al. Survey of yeast mastitis in dairy herds of small-type farms in the Lublin region, Poland. Mycopathologia, v.150, p.5-7, 2000.

KRUKOWSKI, H.; SABA, L. Bovine mycotic mastitis (a review). Folia Veterinaria, v.47, p.3-7, 2003.

KRUKOWSKI, H. et al. Yeasts and algae isolated from cows with mastitis in the south-eastern part of Poland. Polish Journal of Veterinary Sciences, v.9, p.181-184, 2006.

KRZYZANOWSKI, J.; SIELICKA, B. Characteristics of yeasts isolated from clinical cases of mastitis in cows. Annales Universitatis Mariae Curie Skodowska Sectio DD, Medicina Veterinaria, v.51, p.59-64, 1996.

KUO, C.C.; CHANG, C.H. Isolation of yeasts from mastitis milk of dairy cattle. Journal of the Chinese Society of Veterinary Science, v.19, p.221-227, 1993.

KUO, C.C. Clinical and histophatological changes in experimental Candida tropicalis infection in the bovine mammary gland. Journal of the Chinese Society of Veterinary Science, v.19, p.90-97, 1993.

LAGNEAU, P.E. et al. Isolation of yeasts from bovine milk in Belgium. Mycopathologia, v.135, p.99-102, 1996.

LANGONI, H. et al. Participação de leveduras, algas e fungos na mastite bovina. Veterinária e Zootecnia, v.10, p.89-98, 1998.

LASSA, H.; MALINOWSKY, E. Resistance of yeasts and algae isolated from cow mastitic milk to antimicrobial agents. Bulletin of the Veterinary Institute in Pulawy, v.51, p.575-578, 2007.

LOFTSGARD, G.; LINDQUIST, K. Bovine mycotic mastitis. Acta Veterinaria Scandinavica, v.1, p.201-220, 1960.

LOKEN H.I. et al. Infection of the bovine udder with Candida tropicalis. Clinical Date, v.134, p.401-403, 1959.

LOPANDIC, K. et al. Identification of yeasts associeated with milk products using traditional and molecular techniques. Food Microbiology, v.23, p.341-350, 2006.

MANJEET, S. et al. Biochemical changes in milk in Cryptococcal mastitis of experimental goats. Indian Journal of Dairy Science, v.47, p.1043-1049, 1994.

MOAWAD, A.A.; OSMAN, S.A. Prevalence an d aetiology of subclinical mastitis in dairy ewes at Fayoum Governorate, Egypt. Veterinary Medical Journal, v.51, p.135-149, 2005
MORETTI, A. et al. Relationship between cell counts in bovine milk and the presence of mastitis pathogens (yeasts and bacteria). Zentralbl Veterinarmed, v.45, p.129-132, 1998.

NEUFELD, P.M. Manual de micologia médica: técnicas basicas de diagnostico. Rio de Janeiro: PNCQ, 1999. 230 p.

NOBRE, M.O. et al. Drogas antifúngicas para pequenos e grandes animais. Revisão bibliográfica. Ciência Rural, v.32, p.175184, 2002

ODDS, F.C. Candida and candidosis. London, Bailliere Tindall, 1988. 382p.

OLIVEIRA, R.D.R. et al. Infecção hospitalar por leveduras do gênero Candida. Revista da Associação Médica do Brasil, v.51, p.231-235, 2001.

PAL, M. Mastitis in a water buffalo (Bubalus bubalis) due to Cryptococcus neoformans var. neoformans. Revista Iberoamerivana de Micologia, v.8, p.89-91, 1991.

PASCHOAL, J.J. et al. Efeito da suplementação de selênio e vitamina E sobre a incidência de mastite clínica em vacas da raça holandesa. Arquivo Brasileiro de Medicina Veterinária e Zootecnia, v.55, n.3, p.249-255, 2003.

PENGOV, A. Significance of bovine mycotic mastitis. In: III MIDDLE-EUROPEAN CONGRESS FOR BUIATRICS. HEALTH PROBLEMS IN RUMINANTS, 2001, Républica Theca. Anais... República Tcheca: III MIDDLE-EUROPEAN CONGRESS FOR BUIATRICS. HEALTH PROBLEMS IN RUMINANTS, 2001, p.105-107.

RADOSTIS, O.M. et al. Mastite. In: Clinica veterinaria - um tratado de doenças dos bovinos, ovinos, suinos, caprinos e equinos. 9.ed. Rio de Janeiro: Guanabara Koogan, 2002. p.541-629.

RAINARD, P.; RIOLLET, C. Innate immunity of the bovine mammary gland. Review article. Veterinary Research, v.37, p.369-400, 2006.

RICHARD, J.L. et al. Identification of yeasts from infeted bovine mammary glands and their experimental infectivity in cattle. American Journal of Veterinary Research, v.48, p.1991-1994, 1980

ROOSTITA, R.; FLEET, G.H. Growth of yeasts in milk and associated changes to milk composition. International Journal of Food Microbiology, v.31, p.205-219, 1996.

RUZ-PEREZ, M. et al. Pesquisa de fungos no leite de tanques de refrigeração de propriedades de exploração leiteira. Arquivo Instituto Biologico, v.71, p.663-665, 2004.

SANTOS, R.C.; MARIN, J.M. Isolation of Candida spp. from mastitic bovine milk in Brazil. Mycopathologia, v.159, p.251253, 2005.

SHNAWA, I.M.S.; NIGAM, J.M. A note on cryptococca mastitis in sheep. Indian Veterinary Medical Journal, v.7, p.175-176, 1987.

SPANAMBERG, A. et al. Diversity and enzyme production by yeasts isolated from raw milk in Southern Brazil. Acta Scientiae Veterinaire, v.32, p.195-199, 2004 
SPANAMBERG, A. et al. Diversity and antifungal susceptibility of yeasts isolated from raw goat milk and cheese in southern Brazil. In: CONGRESS OF THE INTERNATIONAL SOCIETY FOR HUMAN AND ANIMAL MYCOLOGY, 16., 2006, Paris. França. Anais...Paris: Congres of Internacional Society For Human and Animal Mycology, 2006. p.42.

SPANAMBERG, A. et al. Diversity of yeasts from bovine mastitis in southern Brazil. Revista Iberoamericana de Micologia, v.25, n.3, p. 154-156, 2008 a.

SPANAMBERG, A. et al. Efeito do congelamento sobre a viabilidade de células leveduriformes. Acta Scientiae Veterinaire, v.36, n.1, p.43-54, 2008b.

SWINNE, D. et al. Identification of yeasts from Individual farm tank milk samples in Belgium. Vlaams Diergeneekunding Tijdschrift, v.66, p.129-130, 1997.

THOMPSON K,G. et al. Mycotic mastitis in two cows. New Zealand Veterinary Journal, v.26, p.176-177, 1978.

VACHLU, J; KOUR, A. Yeast lipases: enzyme purification, biochemical properties and gene cloning. Electronic Journal of Biotechnology, v.9, n.1, p.69-75, 2006.

VERMA, P.C. et al. Some aspects os histochemical studies in experimentally produced mycotic mastitis. Haryana Veterinarian, v.14, p.27-34, 1985.
VESTWEBER, J.G.; LEIPOLD, H.W. Pulmonary and mammary aspergillosis in a dairy cow. Canadian Veterinary Journal, v.35, p.780, 1995.

VICTORIA, C.; LANGONI, H. Occurrence of clinical and subclinical mastitis in dairy herd caused by Trichosporon beigelli. Brazilian Journal of Veterinary Research and Animal Science, v.43, p. 280-282, 2006.

YAMAMURA, A.A.M. et al. Isolamento de Prototheca spp. de vacas com mastite, de leite de tanques de expansão e do ambiente de animais. Semina: Ciências Agrarias, v.28, p.105-114, 2007.

YAMAMURA, A.A.M. et al. Risk factors associated with bovine mastitis caused by Prototheca zopfii. Ciência Rural, v.38, n.3, p.755-760, 2008.

YARROW, D. Methods for the isolation, maintence and identification of yeasts. In: KURTZMAN, C.P.; FELL, J.W. (Eds.). The yeasts, a taxonomic study. Amsterdam: Elsevier Science, 1998. p.77-100.

YEH, S.G. et al. Prevalence of yeasts in bovine mammary gland infections and teat cups of milking machines. Korean Journal Veterinary Research, v.28, p.361, 1988.

WAWRON, W.; SZCZUBIAL, M. Treating mastitis mycotica in cows. Medycyna Weterynaryjna, v.57, p.863-866, 2001.

WESTALL, S.; FILTENBORG, O. Spoilage yeasts of decorated soft cheese packet in modified atmosphere. Food Microbiology, v.15, p.243-249, 1998. 